\title{
Is periodontitis a predictor for an adverse outcome in patients undergoing coronary artery bypass grafting (CABG)?
}

\author{
Stefan Reichert ${ }^{1}$, Susanne Schulz ${ }^{1}$, Lisa Friebe ${ }^{1}$, Michael Kohnert ${ }^{1}$, Julia Grollmitz ${ }^{1}$, \\ Hans-Günter Schaller ${ }^{1}$, and Britt Hofmann ${ }^{1}$ \\ ${ }^{1}$ Martin-Luther-Universitat Halle-Wittenberg
}

August 11, 2020

\begin{abstract}
Background: Periodontitis is a risk factor for atherosclerosis and coronary heart disease (CHD). This research evaluated the relationship between periodontal conditions and postoperative outcome in patients undergoing coronary artery bypass grafting (CABG). Methods: 101 patients with CHD (age 69 years, $88.1 \%$ males) and the necessity of a CABG surgery were included. Periodontal diagnosis was made according to the current classification of periodontal diseases (2018) and the guidelines of the "Centers for Disease Control and Prevention" (2007). Additionally, periodontal epithelial surface area (PESA) and periodontal inflamed surface area (PISA) were determined. Survival analyses were carried out after a one-year follow-up period with KaplanMeier survival plots and Logrank test. Hazard ratios (HRs) were determined using Cox regression. Results: 14 patients (13.9 $\%)$ suffered from a new cardiovascular event (11 x angina pectoris, $2 \mathrm{x}$ cardiac decompensation, $1 \mathrm{x}$ cardiac death). Patients with an event reported significantly more often tooth loss probably caused by periodontitis among 1 st degree relatives, $($ HR $=$ $2.2,95 \%$ CI 1.1-4.4, $\mathrm{p}=0.006)$. No other periodontological parameter was significantly associated with the outcome. Internal risk factors were a history of peripheral arterial disease $(\mathrm{HR}=3.7,95 \%$ CI 1.-11.4, $\mathrm{p}=0.013)$, history of myocardial infarction $(\mathrm{HR}=4.0,95 \% \mathrm{CI} 1.4-11.5, \mathrm{p}=0.006)$ and borderline significant previous atrial fibrillation $(\mathrm{HR}=2.9,95 \% \mathrm{CI} 0.9-9.4, \mathrm{p}$ $=0.056)$. Conclusion: Putative familial aggregation of periodontitis but not severity of the disease was associated with new adverse events after CABG surgery.
\end{abstract}

\section{1 | Introduction}

Cardiovascular diseases (CVDs) are the number one cause of death globally. In 2016, CVDs representing $31 \%$ of all global deaths. According the 30th German national heart report published in 2018 coronary heart disease (CHD) with $7.9 \%$ and acute myocardial infarction with $5.3 \%$ were the leading causes of death in Germany. The treatment of patients with CHD is one of the most common medical tasks in developed industrial countries.

Coronary Artery Bypass Grafting (CABG) surgery is considered proven cardiac surgery standard procedure for patients with coronary multivessel disease and / or main coronary stenosis. CABG survival rates depend amongst other things on age. For instance in patients $>70$ years of age, 4-year adjusted survival rate for CABG was $95.0 \%$, in patients 70 to 79 years of age, survival rate was $87.3 \%$, and in patients [?] 80 years of age, survival was $77.4 \%$. Other independent predictors for mortality after CABG were emergency operation, shock, preoperative renal failure, total bypass time, intraoperative stroke, postoperative myocardial infarction, gastrointestinal complications, respiratory failure .

Periodontitis is a chronic multifactorial host mediated inflammatory disease associated with dysbiotic plaque biofilms and characterized by progressive destruction of the tooth-supporting apparatus . In a lot of crosssectional and longitudinal studies a significant association was demonstrated between periodontitis and CVD [, independently of already known risk factors. 
Many studies indicate a direct, biologically plausible relationship between periodontitis and CVD. The local host inflammatory response induced by periodontal pathogens promotes the passage of these microorganisms into the blood circulation. Such bacteremia and/or endotoxemia can be caused by invasive dental treatment such as scaling and root planing or even normal daily activities, like tooth brushing, flossing or food intake and is furthermore associated with the severity of periodontal disease. DNA of key bacteria for periodontitis have been found in both in atheromas and heart tissue. In another studyAggregatibacter actinomycetemcomitans was cultured from both, speciemens taken from periodontal pockets and atheromathous plaque at the same patient. This finding suggests that living bacteria can get from the oral cavity into the coronary arteries and may directly contribute to the pathogenesis of atherosclerosis. In animal experiments, another study showed that Porphyromonas gingivaliscan invade into heart tissue that has already been damaged by ischemia . This result could indicate that periodontal bacteria not only play a role in the development of atherosclerosis, but can also influence the cardiovascular outcome after a primary event.

Periodontitis and the associated increased bacterial load can also have an indirect proatherogenic and prothrombotic effect. Periodontitis was found associated to increased plasma lipid concentration, increased permeability of the coronary endothelium and increased binding of lipoproteins in the intima . Moreover, periodontitis is associated with an elevated general inflammatory status e.g. an increased level of C-reactive protein (CRP) promotes several proatherogenic and prothrombotic mechanisms such as endothelial dysfunction, monocyte-endothelial cell adhesion, accumulation of low-density lipoproteins (LDL) in macrophages, platelet aggregation, reactive oxygen species production, and decrease production of nitric oxide in endothelial cells .

Progression of CVD may be influence by successful periodontal treatment independent of traditional risk factors. Since periodontitis is an important factor in the pathogenesis of atherosclerosis, the aim of the present study was to investigate whether the periodontal status is associated with the postoperative course after CAGB surgery in patients with CHD. If such a relation would be found periodontal diagnosis and, if necessary, periodontal therapy early before CABG surgery may be indicated.

\section{$2 \mid$ methods}

\section{1 | Patients with CHD}

Out of a population of 308 patients 102 patients with CHD for whom an CABG surgery was indicated were included at the department of cardiothoracic surgery of the Heart Centre of the University Clinics Halle (Saale) in the study between January and October 2017. Follow-up data were generated from 101 patients between January 2018 to June 2019 (drop out rate 0.98\%) (Fig. 1). An experienced cardiac surgeon diagnosed patients with CHD and checked the inclusion and exclusion criteria. The following inclusion criteria had to be met: age $>18$ years, at least $60 \%$ stenosis of one of the main coronary arteries demonstrated by angiography, presence of at least four teeth. Exclusion criteria were inability to give written informed consent, subgingival scaling and root planing and/or antibiotic therapy during the last 6 months prior to the examination, pregnancy, and the need of antibiotic prophylaxis against endocarditis according to the criteria of the German Society for Cardiology . Moreover, patients with diseases or disorders such as current drug or alcohol abuse that preclude participation in this clinical study according to investigator judgment were excluded. In order to be able to assess the severity of the CHD the number of coronaries affected was determined (one-, two- or threevessel disease). In addition, Canadian Cardiovascular Society (CCS) stages for angina pectoris were determined. Baseline variables such as age, smoking status (never, past, current smokers and pack years) and current or past diseases (e.g., diabetes mellitus, hypertension, peripheral arterial disease, and dyslipoproteinemia) were assessed as part of the patient's medical history. A person who smoked a minimum of one cigarette per day at the time of questioning was considered to be a current smoker. A past smoker did not smoke for at least one year at the time of the survey. The number of pack years was calculated by multiplying the number of packs of cigarettes smoked per day by the number of years of smoking. Furthermore, all patients underwent detailed clinical and biochemical investigation. For instance, intake of drugs such as lipid lowering drugs, oral anticoagulants, and antiarrhythmics have been registered. Serum parameters including INR (International Normalized Ratio) score, hemoglobin (Hb) 
$[\mathrm{mmol} / \mathrm{l}]$, hematocrit $[1 / \mathrm{l}]$, creatinine $[\mu \mathrm{mol} / \mathrm{l}]$, urea $[\mathrm{mmol} / \mathrm{l}]$, glycated hemoglobin $(\mathrm{HbA} 1 \mathrm{c})[\mathrm{mmol} / \mathrm{mol}]$,$] ,$ C-reactive protein $(\mathrm{CRP})[\mathrm{mg} / \mathrm{dl}]$, leukocytes $[\mathrm{Gpt} / \mathrm{l}]$, and platelets $[\mathrm{Gpt} / \mathrm{l}]$ were recorded.

The dental anamnesis and examination was done one day before the CABG surgery. The patients were asked about the frequency of brushing teeth per day and whether they practiced interdental hygiene using dental floss or interdental brushes. Furthermore, the question was asked whether periodontal therapy in form of scaling and root planing had ever been carried out. In order to be able to estimate an increased occurrence of severe periodontitis within a family, the patients were asked whether there was premature tooth loss due to tooth loosening within relatives of the first degree.

Before the dental examination, the study participants were asked to rinse with an antibacterial mouthwash solution (Chlorhexamed® FORTE alcohol-free $0.2 \%$, GlaxoSmithKline Consumer Healthcare GmbH \& Co. $\mathrm{KG}$, Munich, Germany) in order to reduce the risk of bacteremia due to the probing of dental pockets. The clinical dental assessment involved determining the plaque index (PI) and bleeding on probing (BOP) . In plaque index four tooth surfaces were evaluated mesio-buccal, mid-buccal, disto-bucca, lingual). In bleeding index six sites around each tooth (mesio-buccal, mid-buccal, disto-buccal, disto-oral, mid-oral, mesio-oral) were examined. BOP was only evaluated after a waiting time of 30 seconds after probing.

The measurements for both maximal clinical probing depth $(\mathrm{PD}=$ distance between gingival margin and the apical stop of the probe) and maximum clinical attachment loss $(\mathrm{CAL}=$ distance between the cementoenamel junction and the apical stop of the probe) were taken also at six sites around each tooth. The maximum values for each tooth were taken to calculate the overall mean per participant. In order to obtain reproducible results for BOP, PD, and CAL, the two examiners (L.F. and J.G.) were particularly trained in using a pressure-sensitive dental probe UNC $15(0.2 \mathrm{~N})$ (Aesculap, Tuttlingen, Germany) and calibrated. Particular attention was paid that the examiner oriented the probe in the direction of the tooth axis. The reading was made exactly to the millimeter. If one measuring point (gingival margin or cemento-enamel junction) was between two markers of the measuring scale, the measurement was estimated to $0.5 \mathrm{~mm}$. For the calibration, both examiners determined PD and CAL twice on five periodontal phantom models (phantom model A-PB, frasaco GmbH, Tettnang, Germany) and on five patients. To assess the reproducibility of the double measurements the Bland-Altman method was used. The difference (d) of the two measurements was calculated and plotted against the mean of the two measurements. The measurements are sufficiently reproducible if $95 \%$ of the differences (d) are in the range $\mathrm{d} \pm 2 \mathrm{x} \mathrm{s}$, where s denotes the standard deviation of the differences. Regarding our two rater the differences from two measurements for PD and CAL were to $100 \%$ in this range $\mathrm{d} \pm 2 \mathrm{x}$ s. Thus the examiner L.F. and J.G. were able to generate reproducible measurement results.

The clinical periodontitis case definition was held according to the guidelines of the working group of the Centers for Disease Control and Prevention (CDC) and according the consensus report of the 2017 world workshop on the classification of periodontal and peri-implant diseases and conditions. According CDC a severe periodontitis case was diagnosed if at least [?] 2 interproximal sites with CAL [?] $6 \mathrm{~mm}$ (not on same tooth) and [?] 1 interproximal site with PD [?] $5 \mathrm{~mm}$ were present. A moderate periodontitis case was diagnosed if at least [?] 2 interproximal sites with CAL [?] $4 \mathrm{~mm}$ (not on same tooth) or [?] 2 interproximal sites with PD [?] $5 \mathrm{~mm}$ (not on one tooth) were present. If no severe or moderate periodontitis was present, periodontitis was diagnosed as mild or absent. When using the new classification, the disease stages I to IV were defined by severity (according to the level of interdental clinical attachment loss, and tooth loss), complexity and extent and distribution. However, since no X-ray images were available, the radiological bone loss could not be taken into account. For this reason too, periodontitis was not classified according to the progression rates $\mathrm{A}$ to $\mathrm{C}$.

For a more accurate quantification of the root surface affected by attachment loss and quantification of the inflamed epithelial surface, both the periodontal epithelial surface area (PESA) and the periodontal inflamed surface area (PISA) were calculated. For that purpose, a freely downloadable (www.parsprototo.info $<$ http://www.parsprototo.info) Excel spreadsheet was used. In order to calculate PESA, data of CAL and recession have to be entered. For the calculation of PISA, sites with BOP have to 
be recorded additionally.

\section{2 | Follow-up}

The follow-up was primarily carried out by telephone interview one year after CAGB surgery. If followup information could not be obtained, we contacted civil registration offices and requested information about current address or date of death. The postoperative outcome was assessed using the MACCE (Major Adverse Cardiac and Cerebrovascular Events) criteria established for patients with CHD: 1. No event 2. Myocardial infarction 3. Low cardiac output syndrome 4. Tachycardia (VT) 5. Angina pectoris 6 . Renewed revascularization surgery 7. Cardiac decompensation 8. Peripheral circulatory failure 9. Stroke / Transient ischemic attack (TIA) / Prolonged reversible ischemic neurological deficit (PRIND) 10. Cardiac death 11. Stroke death 12. Not cardiac death.

\section{3 | Statistics}

Statistical analyses were carried out using the software (SPSS v.25.0 package, IBM, Chicago, IL). Values of p [?] 0.05 were considered significant. Categorical variables were documented as number and the corresponding percentage in brackets. For comparisons, the chi-squared test was employed. If the expected values in one group was $<5$, Fisher's exact test was performed. Metric demographic, clinical, and serological data were checked for normal distribution using the Kolmogorov-Smirnov test and the Shapiro-Wilk test. As none of the metric values were normally distributed, they were plotted as median and $25^{\text {th }} / 75^{\text {th }}$ percentiles. For statistical evaluation, the Mann-Whitney U test was used. For survival evaluation Kaplan-Meier analyses with log-rank test were applied. Hazard ratios were calculated with Cox regression.

The investigations were carried out in accordance with the ethical guidelines of the "Declaration of Helsinki" and its amendment in "Tokyo and Venice". The study was approved by the ethics committee of the MartinLuther University Halle-Wittenberg. Informed written consent was obtained from each patient. Before the start of the investigation the study was registered in the German Clinical Trial Register under the number "DRKS00015776".

\section{3 | Results}

\subsection{Periodontitis and severity of CHD}

The severity of the CHD was determined based on the number of coronaries affected and the CCS scores for angina pectoris. No significant associations between the periodontal status according CDC and these internal conditions could be determined (Table 1). If instead the criteria of the CDC the new classification of periodontitis or the values for PESA and PISA were used to assess the severity of periodontitis, no significance could be achieved either (data not shown)

\section{2 | Cross-section comparisons}

No follow-up data could be collected from one patient. Fourteen (13.9\%) patients experienced a cardiovascular event within the one-year follow-up after CAGB surgery (Fig. 1). Eleven patients suffered from angina pectoris, two patients from cardiac decompensation, and one patient died due to a cardiac cause. Regarding dental conditions patients with new cardiovascular event reported significantly more often about early tooth loss caused by tooth loosening among first-degree relatives. No other dental parameter was significantly associated with the cardiovascular outcome. Instead patients with event suffered significantly more frequently from peripheral arterial disease and reported more often a previous myocardial infarction. Moreover, they took significantly more frequently anticoagulants and antiarrhythmics. In addition, there was a trend for an eleveated number of CHD patients with artrial fibrillation among the event group. (Table 2).

\section{3 | Survival analyses}

All significant variables obtained during the cross-sectional analyses (except intake of antiarrhythmics and oral anticoagulants) as well as atrial fibrillation, periodontal conditions (staging, CDC, PESA and PISA) were checked again using Kaplan-Meier survival analyses and Cox regression. 
Regarding dental parameters only early tooth loss was significantly associated with the incidence of a new adverse events $(\mathrm{HR}=2.25,95 \%$ CI 1.15-4.41, $\mathrm{p}=0.007$, Figure 2$)$. There was only a trend for an adverse outcome in dependence of CDC degree (Figure 3, $\mathrm{p}=0.514$ ), PESA (Figure 4, $\mathrm{p}=0.659$ ), and PISA (Figure $5, \mathrm{p}=0.292$ ) but not significance. Regarding previous internal findings PAD (HR $=3.73,95 \%$ CI 1.22-11.42, $\mathrm{p}=0.013$, Figure 6$)$ and previous myocardial infarction $(\mathrm{HR}=3.97,95 \%$ CI $1.37-11.52, \mathrm{p}=0.006$, Figure 7) remained significant. A clear relationship was shown again between atrial fibrillation and a further event with borderline significance ( $\mathrm{HR}=2.94,95 \%$ CI 0.92-9.40, $\mathrm{p}=0.056$, Figure 8).

\section{4 | Discussion}

Periodontitis has a high worldwide prevalence of $40 \%-50 \%$. This is not only important for oral health because there is increasing evidence that periodontitis can promote the development of atherosclerosis and subsequent diseases such as CHD. The majority of these previous longitudinal studies investigated patient groups without clinical symptoms of atherosclerosis or CVD at baseline. However, in two previous studies, an association between periodontal disease and recurrent cardiovascular events was shown. Therefore, it can be assumed that periodontitis may influence cardiovascular outcome after cardiac surgery. In this study, we examined whether periodontitis was associated with the incidence of new cardiovascular events after CAGB surgery. Different periodontitis classification systems were used in order to compensate disadvantages of a separate classification system. For instance, in both the CDC classification and the new classification system bleeding upon probing is not taken into account. However, in particular the area of the periodontal inflamed tissue may associate with the systemic inflammatory burden. For that reason, PESA and PISA were additionally determined as continuous values. PESA allows determining the amount of periodontal altered pocket epithelium whereas PISA allows determining the amount of inflamed pocket epithelium .

Among our test group, the prevalence of a severe periodontitis $(71.3 \%$, Table 1$)$ was more than two times as high in comparison to the normal population because the "Fifth German Oral Health Study" revealed among younger seniors (65 to 74 year olds) a prevalence of $28.3 \%$ [39]. This result may support the importance of severe periodontitis in the pathogenesis of atherosclerosis and CHD. However, after cross-sectional comparisons and survival analyzes, we were unable to ascertain that clinical parameters of periodontitis, oral hygiene habits but also the caries index were significantly associated with the incidence of new cardiovascular events. Only a history of early tooth loss due to tooth loosening among first-degree relatives was associated with increased HR for new cardiovascular events. Regarding the internal parameters, a PAD and a previous myocardial infarction were significant and atrial fibrillation was marginally significant associated with a new event. Oral anticoagulants and antiarrhythmic drugs were also significantly associated with a new event, according to cross-sectional comparisons. Since both drugs are mainly given to patients with atrial fibrillation, no separate survival analyses were carried out.

The hypothesis that clinical parameters of periodontitis and oral hygiene habits influence the follow-up after CABG surgery has not been confirmed by our study. However, the association of a putative familial aggregation of periodontitis assessed as early tooth loss according tooth loosening with the cardiovascular endpoint could be important and should be replicated in further studies. The following hypotheses for this association are conceivable. At first, members of a family share conditions, e.g. less self-care, which promote periodontal disease and CHD. This hypothesis is contradicted by the fact that we could not demonstrate any significant differences in dental care and plaque index between the groups with and without the event. Secondly, this observation may indicate the existence of common genetic risk markers for periodontitis and CHD. A single nucleotide polymorphisms (SNPs) in long non-coding RNA ANRIL (antisense noncoding RNA in the INK4locus) were shown to be associated with both, CHD and periodontitis [. Interestingly, genetic variants of ANRIL was associated with the extent of elevated levels of CRP and new adverse events within three years follow-up in patients who had to be hospitalized for treatment CHD .

The positive association between PAD and cardiovascular outcome revealed in our study has been confirmed by others. It was shown that patients with PAD had in particular poorer long-term survival rates after CAGB surgery than patients without PAD. The association between PAD and long-term survival after CABG may have several explanations. PAD may be a marker of more severe atherosclerosis and subsequent 
diseases such as CHD. Another possibility is that in spite of successful CABG surgery, the risk of noncardiac mortality may be increased. Chue et al. found among patients with PAD a higher incidence of comorbidities and they were generally sicker than patients without PAD .

In our study, a history of myocardial infarction was associated with a higher incidence of new adverse events after CABG surgery. Another study supported our results. A history of MI was associated with increased mortality during the first 30 days after CAGB surgery but not thereafter. Furthermore, patients with a history of MI developed more frequently a new MI. Moreover, a previous MI was also associated with a longer total hospital stay mainly caused by new MI, angina pectoris and congestive heart failure .

In our study, we observed a higher incidence of postoperative events in patients with preoperative atrial fibrillation. This result is also supported by further studies. Preoperative atrial fibrillation was found associated with increased late cardiac morbidity and mortality, poor long-term survival, higher risk of allcause mortality, and congestive heart failure.

\subsection{Limitation}

The number of total study participants, especially those with an event, is too small to make any definitive statements. Therefore a larger study with an extended observation time is necessary.

\section{5 | Conclusion}

Familial aggregation of periodontitis but not periodontitis itself was associated with new adverse events after CABG surgery. We confirmed the risk factors PAD, myocardial infarction, and atrial fibrillation known from other studies for poorer outcome after CAGB surgery.

\section{Acknowledgments}

We would like to thank all the patients with coronary heart disease for their cooperation in this study.

Figure legend

Figure 1 Study design and flow

Figure 2 Kaplan-Meyer survival plots for new cardiovascular events after CAGB surgery stratifying for early tooth loss caused be tooth loosening among relatives first degree $(\mathrm{HR}=2.25,95 \%$ CI 1.15-4.41, $\mathrm{p}=$ $0.007)$.

Figure 3 Kaplan-Meyer survival plots for new cardiovascular events after CAGB surgery stratifying for CDC classification of periodontitis $(\mathrm{p}=0.514)$.

FIGURE 4 Kaplan-Meyer survival plots for new cardiovascular events after CAGB surgery stratifying for PESA percentiles $(\mathrm{p}=0.659)$

FIGURE 5 Kaplan-Meyer survival plots for new cardiovascular events after CAGB surgery stratifying for PISA percentiles $(\mathrm{p}=0.292)$

Figure 6 Kaplan-Meyer survival plots for new cardiovascular events after CAGB surgery stratifying for history of peripheral arterial disease $(\mathrm{HR}=3.73,95 \%$ CI 1.22-11.42, $\mathrm{p}=0.013)$.

Figure 7 Kaplan-Meyer survival plots for new cardiovascular events after CAGB surgery stratifying for history of myocardial infarction $(\mathrm{HR}=3.97,95 \%$ CI 1.37-11.52, $\mathrm{p}=0.006)$.

Figure 8 Kaplan-Meyer survival plots for new cardiovascular events after CAGB surgery stratifying for previous atrial fibrillation $(\mathrm{HR}=2.94,95 \%$ CI 0.92-9.40, $\mathrm{p}=0.056)$.

Table 1 Number of affected coronaries and number of CHD patients with angina pectoris (AP) divided according Canadian Cardiovascular Society(CCS) in dependence on severity of periodontitis 


\begin{tabular}{|c|c|c|c|}
\hline Variable & $\begin{array}{l}\text { Moderate } \\
\text { periodontitis } \mathrm{N}=29 \\
\mathrm{~N}(\%)\end{array}$ & $\begin{array}{l}\text { Severe periodontitis } \\
\mathrm{N}=72, \mathrm{~N}(\%)\end{array}$ & $\mathbf{p}$ \\
\hline $\begin{array}{l}\text { Affected coronaries } \\
\text { One-vessel disease } \\
\text { Two-vessel disease } \\
\text { Three-vessel disease }\end{array}$ & $2(6.9) 4(13.8) 23(79.3)$ & $3(4.2) 17(23.6) 52(72.2)$ & 0.494 \\
\hline $\begin{array}{l}\text { AP classification } \\
\text { (CCS) } 01234\end{array}$ & $\begin{array}{l}8(27.6) 4(30.8) 10(34.5) \\
4(13.8) 3(10.3)\end{array}$ & $\begin{array}{l}24(75.0) 9(69.2) 15 \\
(20.8) 14(19.4) 10(13.9)\end{array}$ & 0.668 \\
\hline
\end{tabular}

$\mathrm{P}$ calculated with $\mathrm{Chi}^{2}$-test

Table 2 Demographic, anamnestic and clinical parameters in dependence of the occurrence of adverse cardiovascular events one year after CAGB surgery. Significant differences are indicated with arrows and p-values are in bold.

\begin{tabular}{|c|c|c|c|c|}
\hline Variable & $\begin{array}{l}\text { Entire study } \\
\text { cohort } N=101, \\
\text { median } \\
\left(25^{\text {th }} / 75^{\text {th }}\right. \\
\text { percentil }) \text { or } N \\
(\%)\end{array}$ & $\begin{array}{l}\text { Event } \mathrm{N}=14, \\
\text { median } \\
\left(25^{\text {th }} / 75^{\text {th }}\right. \\
\text { percentil) or } \mathrm{N} \\
(\%)\end{array}$ & $\begin{array}{l}\text { No event } N=87 \text {, } \\
\text { median } \\
\left(25^{\text {th }} / 75^{\text {th }}\right. \\
\text { percentil }) \text { or } N \\
(\%)\end{array}$ & P- values \\
\hline $\begin{array}{l}\text { age (years) } \\
\text { females males }\end{array}$ & $\begin{array}{l}69.0(60.0 / 75.0) \\
12(11.9) 89 \\
(88.1)\end{array}$ & $\begin{array}{l}71.0(60.8 / 75.3) 2 \\
(14.3) 12(85.7)\end{array}$ & $\begin{array}{l}69.0(60.0 / 74.0) \\
10(11.5) 77 \\
(88.5)\end{array}$ & $0.646^{*} 0.671^{* * *}$ \\
\hline $\begin{array}{l}\text { Body mass index } \\
\left(\mathrm{kg} / \mathrm{m}^{2}\right)\end{array}$ & $28.7(25.6 / 31.0)$ & $29.7(25.4 / 31.8)$ & $28.7(25.6 / 30.5)$ & $0.476^{*}$ \\
\hline $\begin{array}{l}\text { Smoking current } \\
\text { past never pack } \\
\text { years }\end{array}$ & $\begin{array}{l}22(21.8) 42 \\
(41.6) 37(36.6) \\
7.5(0 / 22.5)\end{array}$ & $\begin{array}{l}3(21.4) 6(42.9) 5 \\
(35.7) 3.0(0 / 21.3)\end{array}$ & $\begin{array}{l}19(21.8) 36 \\
(41.4) 32(36.8) \\
8.0(0 / 22.5)\end{array}$ & $0.995^{* *} 0.686^{*}$ \\
\hline $\begin{array}{l}\text { Affected } \\
\text { coronaries } \\
\text { One-vessel disease } \\
\text { Two-vessel } \\
\text { disease } \\
\text { Three-vessel } \\
\text { disease Angina } \\
\text { pectoris grade } \\
\text { CCS 0 CCS I } \\
\text { CCS II CCS III } \\
\text { CCS IV }\end{array}$ & $\begin{array}{l}5(5.0) 21(20.8) \\
75(74.3) 32 \\
(31.7) 13(12.9) \\
25(24.8) 18 \\
(17.8) 13(12.9)\end{array}$ & $\begin{array}{l}2(14.3) 3(21.4) 9 \\
(64.3) 7(50) 1 \\
(7.7) 2(14.3) 2 \\
(14.3) 2(14.3)\end{array}$ & $\begin{array}{l}3(3.4) 18(20.7) \\
66(75.9) 25 \\
(28.7) 12(13.8) \\
23(26.4) 16 \\
(18.4) 11(12.6)\end{array}$ & $0.214^{* *} 0.599^{* *}$ \\
\hline
\end{tabular}




\begin{tabular}{|c|c|c|c|c|}
\hline Variable & $\begin{array}{l}\text { Entire study } \\
\text { cohort } \mathrm{N}=101, \\
\text { median } \\
\left(25^{\text {th }} / 75^{\text {th }}\right. \\
\text { percentil }) \text { or } \mathrm{N} \\
(\%)\end{array}$ & $\begin{array}{l}\text { Event } \mathrm{N}=14, \\
\text { median } \\
\left(25^{\text {th }} / 75^{\text {th }}\right. \\
\text { percentil }) \text { or } N \\
(\%)\end{array}$ & $\begin{array}{l}\text { No event } N=87 \text {, } \\
\text { median } \\
\left(25^{\text {th }} / 75^{\text {th }}\right. \\
\text { percentil }) \text { or } N \\
(\%)\end{array}$ & P-values \\
\hline $\begin{array}{l}\text { History of } \\
\text { Diabetes mellitus } \\
\text { Hypertension } \\
\text { Dyslipoproteine- } \\
\text { mia Peripheral } \\
\text { arterial dis. CVD } \\
\text { MI stroke/TIA } \\
\text { Angina pectoris } \\
\text { PTCA/stent } \\
\text { Atrial fibrillation } \\
\text { Dental } \\
\text { anamnesis tooth } \\
\text { brushing/d 1x } 2 \mathrm{x} \\
3 \mathrm{x} \text { Use of } \\
\text { loss/interdental } \\
\text { brushes previous } \\
\text { SRP Early tooth } \\
\text { loss by tooth } \\
\text { loosening among } \\
\text { related 1st degree }\end{array}$ & $\begin{array}{l}40(39.6) 88 \\
(87.1) 81(80.2) \\
16(15.8) 39 \\
(38.6) 28(27,7) 9 \\
(8.9) 75(74.3) 15 \\
(14.9) 14(13.9) \\
15(14.9) 80 \\
(79.2) 6(5.9) 29 \\
(28.7) 12(11.9) \\
26(25.7)\end{array}$ & $\begin{array}{l}7(50) 14(100) 13 \\
(92.9) 5(35.7)- \\
5(35.7) 8(57.1) \\
-0(0) 10(71.4) \\
3(21.4) 4(28.6) 1 \\
(7.1) 12(85.7) 1 \\
(7.1) 5(35.7) 3 \\
(21.4) 8(51.7)-\end{array}$ & $\begin{array}{l}33(37.9) \\
(85.1) 68(78.2) \\
11(12.6) 34 \\
(39.1) 20(23.0) 9 \\
(10.3) 65(74.7) \\
12(13.8) 10 \\
(11.5) 14(16.1) \\
68(78.2) 5(85.7) \\
24(27.6) 9(10.3) \\
18(20.7)\end{array}$ & $\begin{array}{l}0.397^{* * *} 0.205^{* * *} \\
0.291^{* * *} \\
\mathbf{0 . 0 4 4}^{* * *} 1.00^{* * *} \\
\mathbf{0 . 0 2 0}^{* * *} \\
0.354^{* * *} 0.752^{* * *} \\
0.433^{* * *} 0.102^{* * *} \\
0.678^{* *} 0.563^{* * *} \\
0.366^{* * *} \\
\mathbf{0 . 0 1 4}^{* * *}\end{array}$ \\
\hline $\begin{array}{l}\text { Blood values } \\
\text { INR Hemoglobin } \\
(\mathrm{mmol} / \mathrm{l}) \\
\text { Hematocrit } 1 / 1 \\
\text { Creatinine } \\
(\mu \mathrm{mol} / \mathrm{l}) \text { Urea } \\
(\mathrm{mmol} / \mathrm{l}) \mathrm{HbA} 1_{\mathrm{C}} \\
(\mathrm{mmol} / \mathrm{mol}) \mathrm{CRP} \\
(\mathrm{mg} / \mathrm{L}) \\
\text { Leukocytes } \\
(\mathrm{Gpt} / \mathrm{l}) \text { Platelet } \\
(\mathrm{Gpt} / \mathrm{l})\end{array}$ & $\begin{array}{l}1.04(0.99 / 1.11) \\
8.8(8.3 / 9.4) 0.41 \\
(0.39 / 0.43) 85 \\
(75.5 / 100) 5.9 \\
(4.5 / 7.2) 37.6 \\
(31.2 / 44.4) 2.6 \\
(1.2 / 6.6) 6.5 \\
(7.6 / 9.1) 238.0 \\
(193.0 / 269.5)\end{array}$ & $\begin{array}{l}1.04(0.95 / 1,12) \\
8.4(8.1 / 9.4) 0.4 \\
(0.38 / 0.43) 86.5 \\
(79.5 / 100.3) 6.8 \\
(5.4 / 7.6) 39.0 \\
(35.1 / 52.6) 1.4 \\
(0.7 / 3.9) 7.2 \\
(5.5 / 8.5) 225.0 \\
(184.0 / 259.8)\end{array}$ & $\begin{array}{l}1.04(0.99 / 1.10) \\
8.8(8.3 / 9.4) 0.41 \\
(0.39 / 0.43) 85.0 \\
(74.0 / 99.0) 5.6 \\
(4.3 / 6.8) 40.1 \\
(35.9 / 48.8) 2.8 \\
(1.4 / 6.9) 7.6 \\
(6.6 / 9.5) 239.0 \\
(193.0 / 280.0)\end{array}$ & $\begin{array}{l}0.984^{*} 0.437^{*} \\
0.778^{*} 0.440^{*} \\
0.065^{*} 0.769^{*} \\
0.052^{*} 0.210^{*} \\
0.401^{*}\end{array}$ \\
\hline $\begin{array}{l}\text { Drugs Lipid } \\
\text { lowering drugs } \\
\text { Oral } \\
\text { anticoagulants } \\
\text { Antiarrhythmics }\end{array}$ & $\begin{array}{l}90(89.1) 11 \\
(10.9) 2(2.0)\end{array}$ & $\begin{array}{l}14(100.0) 4 \\
(28.6)-2(14.3) \\
-\end{array}$ & $\begin{array}{l}76(87.4) 7(8.0) 0 \\
(0.0)\end{array}$ & $\begin{array}{l}0.354^{* * *} \\
\mathbf{0 . 0 4 4}^{* * *} \\
\mathbf{0 . 0 1 8}^{* * *}\end{array}$ \\
\hline
\end{tabular}




\begin{tabular}{|c|c|c|c|c|}
\hline Variable & $\begin{array}{l}\text { Entire study } \\
\text { cohort } \mathrm{N}=101, \\
\text { median } \\
\left(25^{\text {th }} / 75^{\text {th }}\right. \\
\text { percentil) or } \mathrm{N} \\
(\%)\end{array}$ & $\begin{array}{l}\text { Event } N=14, \\
\text { median } \\
\left(25^{\text {th }} / 75^{\text {th }}\right. \\
\text { percentil }) \text { or } N \\
(\%)\end{array}$ & $\begin{array}{l}\text { No event } \mathrm{N}=87 \text {, } \\
\text { median } \\
\left(25^{\text {th }} / 75^{\text {th }}\right. \\
\text { percentil) or } \mathrm{N} \\
(\%)\end{array}$ & P- values \\
\hline $\begin{array}{l}\text { Periodontitis } \\
\text { (CDC) No or } \\
\text { mild moderate } \\
\text { severe } \\
\text { Periodontitis } \\
\text { (Staging) } 1234 \\
\text { Plaque index (\%) } \\
\text { Bleeding index } \\
\text { (\%) Pocket depth } \\
\text { (mm)\% sites } \\
\text { with PD }<3 \mathrm{~mm} \\
3-5 \mathrm{~mm}>5 \mathrm{~mm} \\
\text { Attachment loss } \\
\text { (mm) \% sites } \\
\text { with CAL }<3 \mathrm{~mm} \\
3-5 \mathrm{~mm}>5 \mathrm{~mm} \\
\text { PESA (mm }{ }^{2} \text { ) } \\
\text { PISA (mm }{ }^{2} \text { ) } \\
\text { DMF/T Missing } \\
\text { teeth Teeth with } \\
\text { open furcations }\end{array}$ & $\begin{array}{l}0(0.0) 29(28.7) \\
72(71.3) 02(2.0) \\
83(82.2) 16 \\
(15.8) 1.3 \\
(0.9 / 1.7) 18.0 \\
(10.1 / 33.3) 3.0 \\
(2.6 / 3.6) 34.4 \\
(23.3 / 52.7) 56.7 \\
(45.0 / 67.9) 1.7 \\
(0 / 8.3) 3.9 \\
(3.1 / 4.9) 16.7 \\
(3.9 / 32.7) 59.4 \\
(47.4 / 68.5) 12.7 \\
(3.2 / 33.3) 1187.8 \\
(831.4 / 1617.3) \\
194.6 \\
(107.6 / 405.9) 18 \\
(14.0 / 22.0) 7 \\
(3.0 / 15.0) 0 \\
(0 / 2.0)\end{array}$ & $\begin{array}{l}0(0.0) 3(21.4) 11 \\
(78.6) 01(7.1) 10 \\
(71.4) 3(21.4) \\
1.2(0.8 / 1.8) 19.0 \\
(13.8 / 37.0) 2.8 \\
(2.6 / 3.5) 34.8 \\
(23.2 / 59.1) 64.2 \\
(40.7 / 70.5) 1.2 \\
(0 / 5.9) 3.9 \\
(3.1 / 5.0) 13.5 \\
(3.5 / 44.3) 60.0 \\
(44.3 / 76.3) 11.8 \\
(1.8 / 35.0) 1393.7 \\
(966.2 / 1778.6) \\
289.7 \\
(164.8 / 407.9) 16.0 \\
(12.0 / 21.3) 6.0 \\
(2.0 / 9.8) 1.0 \\
(0.0 / 2.0)\end{array}$ & $\begin{array}{l}0(0.0) 26(29.9) \\
61(70.1) 01(1.1) \\
73(83.9) 13 \\
(14.9) 1.3 \\
(1.0 / 1.7) 17.5 \\
(9.6 / 33.3) 3.0 \\
(2.6 / 3.6) 34.4 \\
(23.3 / 52.6) 56.3 \\
(45.2 / 66.7) 1.7 \\
(0 / 9.1) 3.9 \\
(3.2 / 5.0) 19.3 \\
(4.2 / 32.1) 59.4 \\
(48.3 / 68.2) 12.7 \\
(3.2 / 33.3) 1165.2 \\
(812.3 / 1577.9) \\
191.4 \\
(103.1 / 419.9) 19.0 \\
(14.0 / 23.0) 7.0 \\
(3.0 / 17.0) 0.0 \\
(0.0 / 2.0)\end{array}$ & $\begin{array}{l}0.516^{* *} 0.255^{* *} \\
0.293^{*} 0.220^{*} \\
0.738^{*} 0.976^{*} \\
0.353^{*} 0.373^{*} \\
0.705^{*} 0.871^{*} \\
0.596^{*} 0.735^{*} \\
0.453^{*} 0.515^{*} \\
0.266^{*} 0.695^{*} \\
0.517^{*}\end{array}$ \\
\hline
\end{tabular}

CCS, Canadian Cardiovascular Society; CHD, coronary heart disease; CRP, C-reactive proteine; DMF/T, decayed missing filled/teeth; INR, International Normalized Ratio; MI, myocardial infarction; PD, pocket depth; CAL, clinical attachment loss; PESA, periodontal epithelial surface area; PISA, periodontal inflammed surface area; PTCA, percutaneous transluminal coronary angioplasty; SRP, scaling and root planing; TIA, transient ischemic attack

*P calculated with Mann-Withney U-test; ${ }^{* *} \mathrm{P}$ calculated with $\mathrm{Chi}^{2}$-test; ${ }^{* * *} \mathrm{P}$ calculated with Fisher's exact test

\section{Hosted file}

Reichert et al. Figures 2020_08_06.pptx available at https://authorea.com/users/350243/ articles/475112-is-periodontitis-a-predictor-for-an-adverse-outcome-in-patientsundergoing-coronary-artery-bypass-grafting-cabg 